\title{
FLATFOOT CHARACTERISTICS IN SCHOOLCHILDREN DUE TO THEIR CONSTITUTIONAL TYPE FEATURES
}

\section{Andrey Chekhonatsky', Lyudmila Muzurova'2ه, Olga Kondratyeva ${ }^{3}$, Vladimir Chekhonatsky', Olga Fomkina ${ }^{2}$, Yuri Gladilin', Daria Kondratyeva ${ }^{3}$, Valeriy Konnov ${ }^{4}$}

\author{
${ }^{1}$ Department of Neurosurgery, Saratov State Medical University, Saratov \\ ${ }^{2}$ Human anatomy department, Saratov State Medical University, Saratov \\ ${ }^{3}$ N.E. Stern Department of Radiation Diagnostics and Radiation Therapy, \\ Saratov State Medical University Saratov \\ ${ }^{4}$ Department of Orthopedic Dentistry; Saratov State Medical University, \\ Saratov, Russia
}

\section{Imuzurova@yandex.ru}

ABSTRACT - The article offers the results of an anthropometric study of the foot sole (plantography) in schoolchildren, as well as analyzes the dependence that flatfoot features on the body constitution type.

KEYW ORDS - flatfoot, anthropometry, schoolchildren, constitutional type, plantography.

\section{INTRODUCTION}

Mobility plays a very important part in human life nowadays. Living one's life up to the fullest potential implies constant movement, which, in turn, involves health and proper musculoskeletal functioning $[3,6,7]$. The issue of flatfoot has always been in the focus of researchers since it results in fatigue when walking, pain in the feet, knees, hips and lower back, back-pain, and impaired posture $[1,2,4,5]$. Despite a rather wide scatter in the respective figures, most authors agree that this disease is common and affects various groups of the population, especially students. In this regard, studying the correlation of constitutional types and changes in the feet arch in schoolers appears an urgent issue.

Morphological studies require not only a qualitative description of the object studied, yet also a detailed account of its quantitative features $[8,10,13]$. Traditional instrumental and high-tech anthropometric methods, if employed, allow identifying the qualitative and quantitative morphological features of the somatotype, their age- or gender-related, physiological or pathological variability, which, in turn, would offer a chance for an objective and reliable evaluation of the basic anatomical features $[9,11,12,14]$. to identify the patterns of flatfoot in schoolchildren related to the body constitution type.

\section{MATERIALS AND METHODS}

The study was carried out in the Medicine $\&$ Biological School, City of Saratov (Russia) among students aged $12-17$ and attending grades $6-11$. The study involved 145 school students. The anthropometric evaluation was carried out following the generally accepted methodology (V.S. Speransky, V.N. Nikolenko, etc.) employing a standard set of anthropometric tools: a measuring tape (cloth; in centimeters; step $-1 \mathrm{~mm}$ ), electronic medical scales and a plastic height meter $($ step $-1 \mathrm{~cm})$. The plantographic study was carried out based on the anthropometric points on the foot sole, which were marked on their graphic prints.

\section{Research Methodology:}

- draw a line from the center of the heel print to the interdigital space of the third and fourth toes;

- identify the most protruding points on the inner contour of the foot in the front and heel areas and connect them (tangent AK);

- from the center of the tangent, recover the perpendicular to the intersection with the first line;

- divide the resulting segment into three equal parts. Numbering starts from the inside of the print to the outside. I degree flatfoot - the inner contour of the print falls within the first interval; II degree flatfoot - the inner contour of the print belongs to the second interval; III degree flatfoot - the inner contour lies within the third interval.

Transverse flatfoot detection

— on the foot print, we identify the most prominent points on the inner and outer sides of the forefoot - points $\mathrm{A}$ and $\mathrm{B}$, corresponding to the heads of the $1^{\text {st }}$ and $5^{\text {th }}$ metatarsal bones, and connect them together;

- through point $B$ on the print outer side, and the most prominent heel point, draw a tangent to which we restore the perpendicular running from point $\mathrm{D}$ - the extreme rear point of the heel print, thus getting point $\mathrm{E}$;

- place point $\mathrm{P}$ on the most prominent edge of the big (or second) toe. DP is the print length. 
- multiply the length of the DP segment by 0.16 and measure it from point $\mathrm{E}$ along the $\mathrm{BE}$ line. This is point $\mathrm{C}$. $\mathrm{CE}=0.16 \cdot \mathrm{DP}$;

- from point $\mathrm{C}$ we recover the perpendicular to the $\mathrm{BE}$ line. $\mathrm{CC}$ is the middle calcaneal axis;

- cut the CC\& segment in half, which offers us point $\mathrm{F}$ - the middle calcaneal point;

- cut the $\mathrm{AB}$ segment in half and get point $\mathrm{Z}$;

- connect points $F$ and $Z$ thus getting the conditional foot axis;

- from points $\mathrm{A}$ and $\mathrm{B}$, draw lines $\mathrm{AN}$ and $\mathrm{BR}$ parallel to $\mathrm{FZ}$ (the conditional foot axis);

- from points A and B, draw lines AP and BQ through the extreme front points of the $1^{\text {st }}$ and the $5^{\text {th }}$ toes.

Normally, the angle at the first toe (NAP angle) is below $18^{\circ}$, while the angle at the fifth toe (QBR angle) is less than $12^{\circ}$ (Fig. 1).

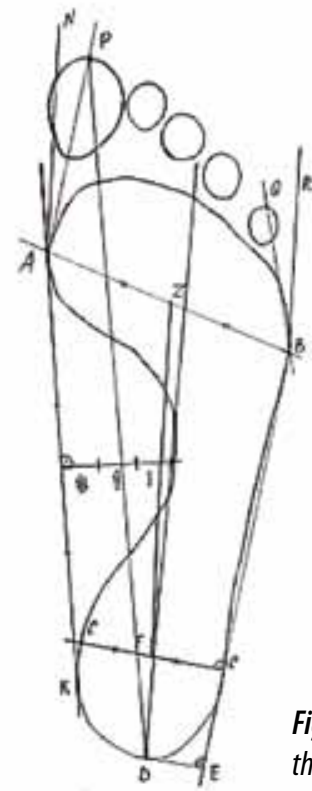

Fig. 1. Anthropometric points of the sole of the foot for plantography

The work implied identifying the body type. The classifications employed here were those by Chernorutsky, Shevkunenko, as well as Vervek index.

1. Chernorutsky identifies 3 body types: asthenic, normosthenic and hypersthenic. To classify a certain person's type involves calculating a numerical index, or Pignet index, which is based on the formula below:

$$
I=L-(M+R)
$$

$L$ - body length (cm), $M$ - body mass $(\mathrm{kg}), R$ chest circumference $(\mathrm{cm})$.

Depending on the numbers obtained, there are 3 types of body to be described:
Asthenic at $I>30$, normostenic $10<I<30$ and hypersthenic $I<10$ types. The lower the numerical index, the larger the body.

2. Shevkunenko mentions brachymorphic, mesomorphic and dolichomorphic body types. The criterion is the ratio of the shoulders width to the length of the entire body. (Less than 22 - dolichomorphism, 22-33 - mesomorphism, above 33 - brachymorphism).

3. Besides, attributing to a particular type can be done through Vervek body mass-to-length index. This is a specific indicator of the harmony of growth. In healthy children, it does not change over age and is calculated by the formula below:

$$
\frac{L}{2 P+R}
$$

$L$ - body length (cm), $P$ - weight $(\mathrm{kg}), R$ - chest circumference $(\mathrm{cm})$. Normally, the index value varies from 0.85 to 1.25 . These are the limits for the mesomorphic body type. The index of 0.85 and below indicates that the child is delayed in growth; in case it is above 1.25 , this is considered to be a sign of dolichomorphism and the predominance of growth in length.

The participants within this study had many indicators examined, namely height, weight, epigastric angle, chest circumference, shoulder width.

To process the obtained data, the RuleMarker program version 2.3 was used (JSC IT Ltd., St. Petersburg, 1992); application package for statistical data processing Statgraphics 4.0; 1D and 2D programs - elementary statistics; Microsoft Excel for Windows 2000 (Microsoft Corp.). Differences in indicators were considered significant at $\mathrm{p}<0.05$.

\section{OR\|G\|NAL DATA}

Based on the classification by Chernorutsky, the students were divided into 3 groups: asthenics (44.8\%), normosthenics (48.1\%), hypersthenics (7.1\%) (Fig. 2).

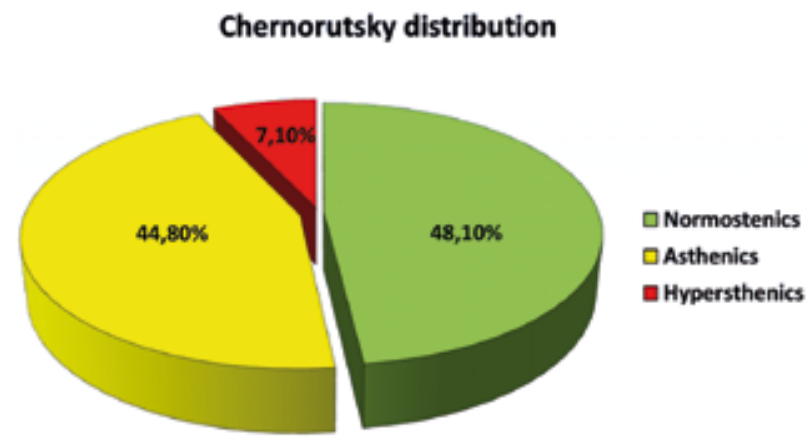

Fig. 2. Distribution by somatic types (\%): normostenics, asthenics, hypersthenics 
Following the classification by Shevkunenko, only schoolers with mesomorphic (93.7\%) and dolichomorphic body types (6.3\%) were identified among the study participants (Fig. 3).

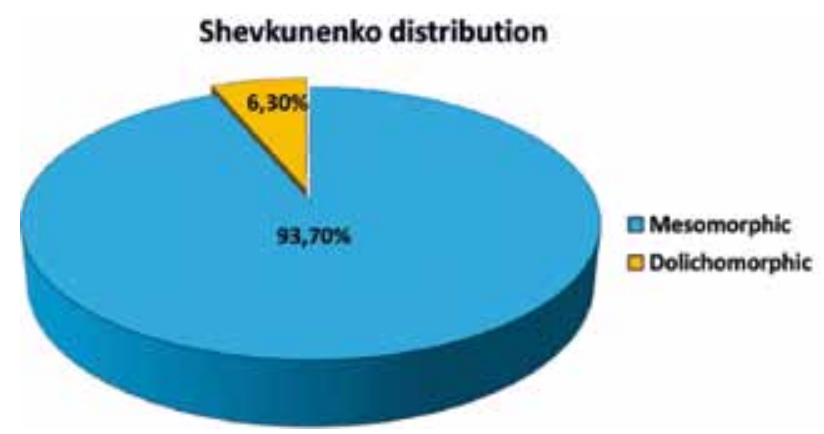

Fig. 3. Distribution of the examined by body type (\%): mesomorphic, dolichomorphic

In most observations (62.2\%), the Vervek index fell within the range of 1.25-0.85 units, which indicates harmonious development; $37.8 \%$ of the observations in the group revealed delay (index below 0.75 units), while no tall students were observed in this sample (1.35-1.25 units) (Fig. 4).

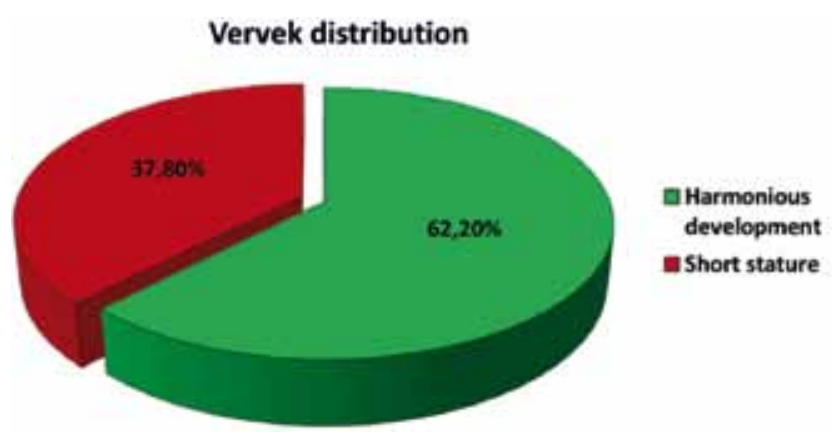

Fig. 4. The occurrence of harmonious development (\%): harmonious development, short stature

Table 1 shows the results for all the students involved in the study.

The weight of the students varied from 34 to 84 $\mathrm{kg}$, the average of that being $55.4 \mathrm{~kg}$; the variability for this feature was average (16.5\%). This is the highest indicator of the variability coefficient of all the features taken into account. The average height was $166.17 \mathrm{~cm}$. In general, this feature varies from 140 to $190 \mathrm{~cm}$. The variability coefficient was low $(5.16 \%)$. The chest circumference varied from 65 to $103 \mathrm{~cm}$, the variability is low $(7.15 \%)$, which is slightly above that of the height variability. The average value feature was
$82.05 \mathrm{~cm}$. The shoulder width was within the range of $34-51$, the variability was low (7.69\%), the average value $-40.88 \mathrm{~cm}$.

Tables 2 and 3 present the results of a survey involving high school students of 2 age groups: youth and adolescents. The average weight for the students in the youth group was $55.94 \mathrm{~kg}$, which is $1.8 \mathrm{~kg}$ above the average weight of those belonging to the adolescent group. This feature in the first group (adolescents) is more variable than in the other (youth), the coefficient in the $1^{\text {st }}$ case was $18.84 \%$, in the second $14.48 \%$. In the adolescent group, the feature ranged from 34 to $84 \mathrm{~kg}$, in the group of young students - from 41 to $76 \mathrm{~kg}$. The boundaries of the feature in the first group were reliably wider than in the second. The height of adolescent students ranged from 140 to $183 \mathrm{~cm}$, among the youth - from 152 to $190 \mathrm{~cm}$. The height variability coefficient for the adolescents, as in the case with the weight, was $0.25 \%$ higher. The average height in the group of adolescents was $162.61 \mathrm{~cm}$, which is $5.39 \mathrm{~cm}$ below the average height in the group of the youth $(168 \mathrm{~cm})$.

The chest circumference in the adolescents ranged from 64 to $103 \mathrm{~cm}$, and among the young students - from 64 to $97 \mathrm{~cm}$. The variability coefficient for this feature in the first group was $7.86 \%$, which is $1.35 \%$ above that in the second one, where it was $6.51 \%$. The average value of this feature in the second group was higher than in the first group exceeding it by $0.91 \mathrm{~cm}$. The shoulder width in the group of adolescents ranged from 35 to $51 \mathrm{~cm}$, in the youth group it fell between 34 and $48 \mathrm{~cm}$. The variability coefficient was $7.43 \%$ in the first group and $7.68 \%$ in the second. The average value of this feature for the young students was slightly lower compared to the adolescents and was $40.43 \mathrm{~cm}$ and $41.51 \mathrm{~cm}$, respectively.

Tables 4 and 5 present the results investigating the morphometric features of girls and boys. The average weight for the girls was $53.46 \mathrm{~kg}$, the feature was less variable (coefficient $-14.44 \%$ ). In young men, the variability coefficient was $18.56 \%$ (average variability). The average height for the girls was below that in boys by $6.13 \mathrm{~cm}(164.14 \mathrm{~cm})$. The same feature for the girls ranged from 150 to 177 , for boys - from 140 to 190 . The respective variability coefficient in the boys' group was $6.02 \%$ (low variability), which is $2.28 \%$ above than the coefficient in the group of the girls. The average chest circumference in girls was smaller than in boys by $1.39 \mathrm{~cm}(82.0 \mathrm{~cm})$. The feature variability in the boys' group was 1.54 times higher than in the group of girls. The feature limits in the young men were wider than in the girls, $64-106 \mathrm{~cm}$ and $71-97 \mathrm{~cm}$, respectively. The shoulder width ranged from 38 to 51 among the boys, and from 34 to 49 - among the girls. The variability 
Table 1. Morphometric features of the entire study population

\begin{tabular}{l|l|l|l|l}
\hline \multirow{2}{*}{ Parameters } & \multicolumn{4}{|l}{ Variational and statistical indicators } \\
\cline { 2 - 5 } & $M \pm m$ & Min-max & $\delta$ & CV\% \\
\hline Weight & $55,4 \pm 0,81$ & $34-84$ & 9,14 & 16,5 \\
\hline Height & $166,17 \pm 0,76$ & $140-190$ & 8,58 & 5,16 \\
\hline Chest circumference & $82,05 \pm 0,52$ & $64-103$ & 5,87 & 7,15 \\
\hline Shoulder width & $40,88 \pm 0,2$ & $34-51$ & 3,14 & 7,69
\end{tabular}

Table 2. Morphometric features of the adolescent students

\begin{tabular}{l|l|l|l|l}
\hline \multirow{2}{*}{ Parameters } & \multicolumn{4}{|l}{ Variational and statistical indicators } \\
\cline { 2 - 5 } & $M \pm m$ & Min-max & $\delta$ & CV\% \\
\hline Weight & $54,14 \pm 1,34$ & $34-84$ & 10,2 & 18,84 \\
\hline Height & $162,61 \pm 0,66$ & $140-183$ & 8,4 & 5,17 \\
\hline Chest circumference & $81,56 \pm 0,84$ & $64-103$ & 6,41 & 7,86 \\
\hline Shoulder width & $41,51 \pm 0,4$ & $35-51$ & 3,08 & 7,43 \\
\hline
\end{tabular}

Table 3. Morphometric features of the students falling in the group of youth

\begin{tabular}{l|l|l|l|l}
\hline \multirow{2}{*}{ Parameters } & \multicolumn{4}{l}{ Variational and statistical indicators } \\
\cline { 2 - 5 } & $\mathrm{M} \pm \mathrm{m}$ & Min-max & $\delta$ & $\mathrm{CV} \%$ \\
\hline Weight & $55,94 \pm 0,96$ & $41-76$ & 8,10 & 14,48 \\
\hline Height & $168 \pm 0,98$ & $152-190$ & 8,27 & 4,92 \\
\hline Chest circumference & $82,47 \pm 0,64$ & $64-97$ & 5,37 & 6,51 \\
\hline Shoulder width & $40,43 \pm 0,37$ & $34-48$ & 3,11 & 7,68 \\
\hline
\end{tabular}

Table 4. Morphometric features of girls

\begin{tabular}{l|l|l|l|l}
\hline \multirow{2}{*}{ Parameters } & \multicolumn{4}{|l}{ Variational and statistical indicators } \\
\cline { 2 - 5 } & $\mathrm{M} \pm \mathrm{m}$ & Min-max & $\delta$ & CV\% \\
\hline Weight & $53,46 \pm 0,87$ & $38-80$ & 7,72 & 14,44 \\
\hline Height & $164,14 \pm 0,7$ & $150-177$ & 6,14 & 3,74 \\
\hline Chest circumference & $82,0 \pm 0,56$ & $71-97$ & 4,86 & 5,90 \\
\hline Shoulder width & $39,86 \pm 0,32$ & $34-49$ & 2,81 & 7,05 \\
\hline
\end{tabular}

Table 5. Morphometric features of boys

\begin{tabular}{l|l|l|l|l}
\hline \multirow{2}{*}{ Parameters } & \multicolumn{4}{|l}{ Variational and statistical indicators } \\
\cline { 2 - 5 } & $\mathrm{M} \pm \mathrm{m}$ & Min-max & $\delta$ & $\mathrm{CV} \%$ \\
\hline Weight & $58,77 \pm 1,42$ & $34-96$ & 10,91 & 18,56 \\
\hline Height & $170,27 \pm 0,79$ & $140-190$ & 10,25 & 6,02 \\
\hline Chest circumference & $83,39 \pm 0,83$ & $64-106$ & 7,59 & 9,10 \\
\hline Shoulder width & $43,23 \pm 0,46$ & $38-51$ & 3,02 & 6,96 \\
\hline
\end{tabular}

in the first case was $6.96 \%$, in the second $-7.05 \%$. The average value in the group of boys was higher than in the group of girls by $3.37 \mathrm{~cm}$.

In order to identify a link between the body constitution and flatfoot, the groups of participants featuring different types of structure, were similar in the number. The comparative data on the foot archas per each type can be seen from Table 6.

Table 6 shows that among asthenics and hypersthenics, 3 out of 10 students have healthy foot arches with no change, which is not much less than among normostenics (4 out of 10).

Among the normostenics, in turn, combined flatfoot occurs more often ( 3 out of 10) than among hypersthenics ( 2 out of 10$)$ and 3 times more often than in case with asthenics (1 out of 10). According to the study, a change in the longitudinal foot arch is more common among asthenics (3 out of 10 ), which is 3 times above normostenics (1 out of 10 ) and 1.6 times above hypersthenics ( 2 out of 10). In turn, changed transverse foot arch in asthenics and hypersthenics reveal similar occurrence ( 3 out of 10 ), which is slightly higher than in normostenics (2 out of 10).

A survey was held among the participants to identify possible causes. For that, the students had to indicate (if present) not only a previously diagnosed flatfoot, yet also talked about their preference of high-heeled shoes (Fig. 5).

\section{CONCLUSION}

Analyzing the obtained data, we can say that the incidence of flatfoot reveals some insignificant dependence on the general body structure. $71.8 \%$ of the students aged 12-18 years revealed changes in the foot arch. The share of change observed in the foot arch 
Table 6. Ratio of students with change observed in the foot arch, and those with no change, per each body constitution type

\begin{tabular}{l|l|l|l}
\hline Type of flat feet & Asthenics & Normostenics & Hypersthenics \\
\hline Transverse & $30 \%$ & $20 \%$ & $30 \%$ \\
\hline Longitudinal & $30 \%$ & $10 \%$ & $20 \%$ \\
\hline Combined & $10 \%$ & $30 \%$ & $20 \%$ \\
\hline Healthy & $30 \%$ & $40 \%$ & $30 \%$ \\
\hline
\end{tabular}

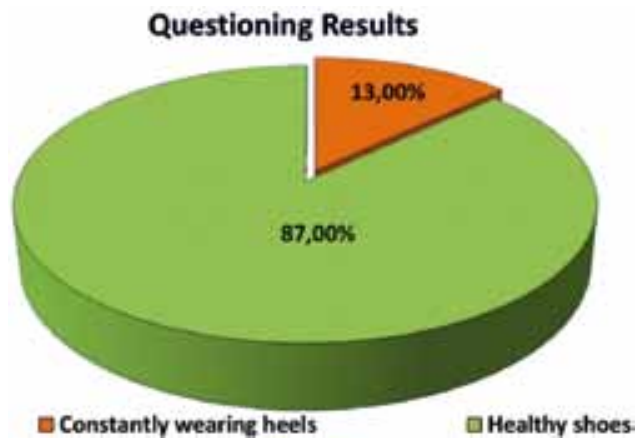

Fig. 5. Footwear preference based on the survey

among girls is higher than among boys (girls - 77.3\%; boys $-60.0 \%$ ), which could be explained by their lifestyle.

\section{REFERENCES}

1. SPERANSKY V.S., Nikolenko V.N. Lectures on medical anthropology, Publishing house of the Saratov Medical University. 2006; 89.

2. Nikolenko V.N., G.A. Dobrovolsky G.A. Teaching aid in medical anthropology; Publishing House of the Saratov Medical University, 2010; 124.

3. Polyakov K.A., Zryachkin N.I., Chebotaryova G.I. Methods for assessing the physical development of preschool children and adolescents. Method. allowance. Sarat Publishing House. honey. University, Saratov. 2009; 59.

4. E.N. Khrisanfova, I.V. Carriers; Medical Anthropology: Textbook .; M .: Moscow Publishing House. University: Science. 2005; 400.

5. Kudentsova G.V. Investigation of the role of genetic and environmental factors in the determination of static flat feet in children: Abstract. diss. ... cand. honey. Sciences: 03.00.15 / Kudentcova Galina Vasilevna. Grew up. state honey. un-t Moscow. 2002. 23.

6. Kenis V.M., Khusannova R.Kh., SAPOgovsky A.V. Mobile flat feet in children (literature review). Pediatric Traumatology, Orthopedics and Reconstructive Surgery. 2014; II (2): 44-54.

7. Blakemore I.C., CoOperman D.R., Thompson G.H. The rigin flatfoot: dorsal coalitions. Clin. Pediatr. Med. Surg. 2000; 17(3): 531-555.
8. Domenyuk D.A., DMitrienko S.V. Porfyriadis M.P. Major telerenthengogram indicators in people with various growth types of facial area // Archiv EuroMedica. 2018. Vol. 8. № 1. P. 19-24.

9. Domenyuk D.A., ShKarin V.V., Porfiriadis M.P., DMitrienko D.S., DMitrienko S.V. Classification of facial types in view of gnathology // Archiv EuroMedica, 2017. Vol. 7. № 1. P. 8-13.

10. Dmitrienko S.V., Domenyuk D.A., Melekhov S.V., Domenyuk S., Weisheim L.D. Analytical approach within cephalometric studies assessment in people with various somatotypes // Archiv EuroMedica. 2019. Vol. 9; 3: 103-111. https://doi. org/10.35630/2199-885X/2019/9/3.29

11. Dmitrienko T.D., Domenyuk D.A., Porfyriadis M.P., ARUTYUNOVA A.G., KondRATYUK A.A., Subbotin R.S. Connection between clinical and radiological torque of medial incisor at physiological occlusion // Archiv EuroMedica. 2019. Vol. 9. № 1. P. 29-37. https://doi.org/10.35630/2199$885 \mathrm{X} / 2019 / 9 / 1 / 29$

12. Dmitrienko S.V., Fomin I.V., Domenyuk D.A., Kondratyuk A.A., Subbotin R.S. Enhancement of research method for spatial location of temporomandibular elements and maxillary and mandibular medial incisors // Archiv EuroMedica. 2019. T. 9. № 1. P. 38-44. https://doi.org/10.35630/2199$885 \mathrm{X} / 2019 / 9 / 1 / 38$

13. ShKarin V.V., IVAnov S.Yu., DMitrienko S.V., DOMENYUK D.A., LePILIN A.V., DOMENYUK S.D. Morphological specifics of craniofacial complex in people with various types of facial skeleton growth in case of transversal occlusion anomalie // Archiv EuroMedica. 2019. Vol. 9; 2: 5-16. https://doi. org/10.35630/2199-885X/2019/9/2/5

14. Shkarin V.V., Grinin V.M., Khalfin R.A., DMITRIENKo S.V., DomenyUK D.A. Specific features of grinder teeth rotation at physiological occlusion of various gnathic dental arches // Archiv EuroMedica. 2019. Vol. 9; 2: 168-173. https://doi. org/10.35630/2199-885X/2019/9/2/168 